\title{
IDegLira Versus Insulin Glargine U100: A Long-term Cost-effectiveness Analysis in the US Setting
}

\author{
Barnaby Hunt (D) Michelle Mocarski - William J. Valentine • \\ Jakob Langer
}

Received: February 3, 2017 / Published online: March 27, 2017

(C) The Author(s) 2017. This article is an open access publication

\begin{abstract}
Introduction: Treatment with IDegLira has the potential to improve glycemic control in patients with type 2 diabetes mellitus (T2DM) without the weight gain and with a lower risk of hypoglycemia than with other therapies. The aim of the present analysis was to evaluate the long-term cost-effectiveness of IDegLira versus insulin glargine U100 with re-education and up-titration of the dose for treatment of patients with T2DM failing to achieve glycemic control on basal insulin in the US setting.
\end{abstract}

Methods: Data were obtained from the DUAL V randomized controlled trial in which adults with T2DM failing to achieve glycemic targets with insulin glargine U100 were randomly allocated to

Enhanced content To view enhanced content for this article go to http://www.medengine.com/Redeem/08F7 F0601436691B.

Electronic supplementary material The online version of this article (doi:10.1007/s13300-017-0251-x) contains supplementary material, which is available to authorized users.

B. Hunt $(\varangle)$. W. J. Valentine

Ossian Health Economics and Communications

GmbH, Basel, Switzerland

e-mail: hunt@ossianconsulting.com

M. Mocarski

Novo Nordisk Inc., Plainsboro, New Jersey, USA

J. Langer

Novo Nordisk A/S, Søborg, Denmark receive either IDegLira or insulin glargine U100. Long-term projections of clinical outcomes and direct costs were made using the IMS CORE Diabetes Model. Costs were accounted from a healthcare payer perspective. Future costs and clinical benefits were discounted at $3 \%$ annually. Results: IDegLira was associated with improved discounted life expectancy (13.99 [standard deviation 0.19 ] versus 13.82 [standard deviation 0.20 ] years) and quality-adjusted life expectancy (9.14 [standard deviation 0.12] versus 8.87 [standard deviation 0.13] quality-adjusted life years [QALYs]) compared to insulin glargine U100. IDegLira was associated with increased direct costs of $\$ 16,970$, yielding an incremental cost-effectiveness ratio (ICER) of $\$ 63,678$ per QALY gained versus insulin glargine U100. Sensitivity analyses identified that the key driver of cost-effectiveness was the greater reduction in glycated hemoglobin with IDegLira compared with insulin glargine U100.

Conclusions: Based on head-to-head clinical trial data, the present analysis suggests that IDegLira is likely to improve long-term clinical outcomes for patients with T2DM not achieving glycemic control on basal insulin compared to re-education and up-titration of the dose of insulin glargine U100, with these improvements coming at an increased cost from a healthcare payer perspective. An ICER within the range described as high care value was calculated, suggesting IDegLira is a cost-effective treatment option in the US. 
Funding: Novo Nordisk A/S and Novo Nordisk Inc.

Keywords: Basal insulin; Cost; Cost-effectiveness; IDegLira; Insulin glargine U100; Type 2 diabetes mellitus; USA

\section{INTRODUCTION}

Diabetes mellitus represents one of the most significant challenges to healthcare providers globally, and particularly in the USA. Estimates suggest that the global healthcare expenditure as a result of diabetes was $\$ 376$ billion in 2010 , representing $12 \%$ of healthcare expenditure worldwide, and that $52.7 \%$ of the expenditure would occur in the USA alone [1]. The annual cost per person with diabetes was also the highest in the USA at $\$ 7383$, with only four other countries spending over $\$ 4000$ per patient (Austria, France, Sweden, and the Netherlands) [1]. It is estimated that over $40 \%$ of the costs attributable to diabetes in the USA are due to higher rates of hospital admission and increased length of stay, reflecting the burden that diabetes-related complications place on healthcare providers, while medications (including insulin and other treatment options) represent only $28 \%$ of the costs attributable to diabetes [2].

The progressive nature of type 2 diabetes mellitus (T2DM) means that, while patients may often be initially managed with diet and exercise alone, there is generally a need to add glucose-lowering medications over time [3]. In the majority of cases, patients will ultimately initiate insulin therapy having failed to achieve or sustain glycemic targets with lifestyle modifications, oral antidiabetic agents, and/or glucagon-like peptide-1 (GLP-1) receptor agonists. Insulin therefore remains a cornerstone of T2DM treatment. Doses of basal insulin can be titrated to maintain glycemic control, although this may be associated with increased rates of hypoglycemia and weight gain $[4,5]$.

An alternative to up-titration of basal insulin may be switching patients failing to achieve glycemic control on basal insulin to IDegLira. IDegLira is a fixed ratio combination of insulin degludec and GLP-1 receptor agonist liraglutide for adult patients with T2DM (50 IU insulin degludec to $1.8 \mathrm{mg}$ liraglutide). The use of GLP-1 receptor agonists and basal insulin in combination is well established, and is recommended in treatment guidelines $[6,7]$. The complementary mechanisms of action of these two agents result in improved glycemic control with low risk of hypoglycemia and avoidance of weight gain [6]. IDegLira represents a fixed-ratio combination of a basal insulin and a GLP-1 receptor agonist in a single injection device.

The cost-effectiveness of IDegLira has been assessed in previous analyses in the UK, Sweden, Spain, Slovakia, and the USA [8-11]. In patients with T2DM failing to achieve glycemic control on basal insulin, IDegLira was found to be dominant over basal-bolus insulin in the UK, Sweden, and Spain, and cost-effective in Slovakia. Compared with liraglutide added to basal insulin, IDegLira has been shown to be dominant in the UK, Sweden, Spain, and the USA. Versus up-titration of basal insulin, IDegLira was found to be cost-effective in the UK and Sweden. The aim of the present analysis was to evaluate the long-term cost-effectiveness of IDegLira versus insulin glargine U100 with re-education and up-titration of the dose for treatment of patients with T2DM failing to achieve glycemic control on basal insulin in the US setting.

\section{METHODS}

\section{Simulated Cohort}

Baseline risk factors and patient characteristics were based on all patients included in the DUAL $\mathrm{V}$ study, with mean baseline cohort characteristics shown in Table 1 [12]. DUAL $\mathrm{V}$ was a phase 3, multinational, 26-week, open-label study comparing the safety and efficacy of IDegLira and insulin glargine U100 in patients with T2DM with HbA1c of $7-10 \%$ who were receiving stable doses of insulin glargine U100 and metformin. In total, 557 patients were randomly allocated to the two treatment arms in a 1:1 ratio. Of these, 39 were residing in the USA with characteristics well matched to participants from other countries. The primary 
Table 1 Baseline cohort characteristics

\begin{tabular}{lcc}
\hline & Mean & Standard deviation \\
\hline Start age (years) & 58.8 & 9.5 \\
Duration of diabetes (years) & 11.5 & 7.0 \\
Percentage male (\%) & 50.3 & - \\
HbAlc $\%)$ & 8.3 & 0.9 \\
Systolic blood pressure (mmHg) & 13.2 \\
Total cholesterol (mg/dL) & 133.0 & 42.9 \\
HDL cholesterol $(\mathrm{mg} / \mathrm{dL})$ & 181.0 & 11.6 \\
LDL cholesterol $(\mathrm{mg} / \mathrm{dL})$ & 46.8 & 35.4 \\
Triglycerides $(\mathrm{mg} / \mathrm{dL})$ & 99.9 & 203.0 \\
BMI $\left(\mathrm{kg} / \mathrm{m}^{2}\right)$ & 182.9 & 4.5 \\
\hline
\end{tabular}

$B M I$ body mass index, $H b A l c$ glycated hemoglobin, $H D L$ high density lipoprotein, $L D L$ low density lipoprotein

endpoint was change from baseline in HbA1c at 26 weeks, with secondary endpoints of change from baseline in body weight at 26 weeks and number of treatment-emergent hypoglycemic episodes during 26 weeks. IDegLira was initiated at a starting dose of 16 dose steps and titrated to a maximum of 50 dose steps, while doses of insulin glargine were titrated from a mean starting dose of $32 \mathrm{IU}$ with no maximum dose. Approximately $40 \%$ of patients in the IDegLira arm received the maximum 50 dose steps after 26 weeks of treatment. Of these patients, $68 \%$ achieved an HbA1c level less than 7\% compared with $74 \%$ of those who used less than the maximum allowed IDegLira dose.

\section{Treatment Effects}

Treatment effects applied in the first year of the analysis were based on the DUAL V study, with inputs taken from the 26-week end of trial data (Table 2) [12]. IDegLira was associated with statistically significant improvements in glycated hemoglobin (HbA1c), systolic blood pressure, total cholesterol, body mass index (BMI), and non-severe hypoglycemic events. It should be noted that HbA1c changes presented for each treatment arm by Lingvay et al. are not adjusted for differences between the IDegLira and insulin glargine arms at baseline, but the estimated treatment difference presented is adjusted for these differences [12]. The present analysis used the adjusted values for each treatment arm, reflecting the estimated treatment difference between the arms presented by Lingvay et al. Patients were assumed to receive IDegLira or insulin glargine U100 for 5 years, before intensifying therapy to basal bolus insulin (insulin glargine U100 plus three times daily insulin aspart). During the period in which patients received initial treatments, HbA1c remained constant, as this is in line with long-term studies of patients with T2DM receiving insulin [13-17]. After intensification at 5 years, HbA1c, BMI, hypoglycemic event rates, and annual costs of T2DM interventions were the same in both treatment arms, with immediate abolition of relative treatment effects representing a conservative modelling approach. Alternative approaches to treatment switching and long-term parameter progression were evaluated in sensitivity analyses.

\section{Utilities and Costs}

To capture the impact of diabetes-related complications on quality of life, utilities were taken from published sources (Table 3). Doses of 
Table 2 Treatment effects

\begin{tabular}{lcc}
\hline & $\begin{array}{l}\text { IDegLira } \\
{[\text { mean }(\mathrm{SD})]}\end{array}$ & $\begin{array}{c}\text { Insulin glargine U100 } \\
{[\mathbf{m e a n}(\mathrm{SD})]^{-}}\end{array}$ \\
\hline HbAlc $\%)$ & $-1.77(0.87)$ & $-1.17(0.87)^{\mathrm{a}}$ \\
Systolic blood pressure $(\mathrm{mmHg})$ & $-3.71(11.80)$ & $-0.15(11.80)^{\mathrm{a}}$ \\
Total cholesterol $(\mathrm{mg} / \mathrm{dL})$ & $-5.34(33.25)$ & $+2.95(33.26)^{\mathrm{a}}$ \\
HDL cholesterol $(\mathrm{mg} / \mathrm{dL})$ & $+1.14(8.19)$ & $+1.23(8.18)$ \\
LDL cholesterol $(\mathrm{mg} / \mathrm{dL})$ & $-4.12(26.23)$ & $+2.58(26.23)$ \\
Triglycerides $(\mathrm{mg} / \mathrm{dL})$ & $-16.03(128.29)$ & $-7.57(128.28)$ \\
Body mass index $\left(\mathrm{kg} / \mathrm{m}^{2}\right)$ & $-0.50(1.22)$ & $+0.67(1.22)^{\mathrm{a}}$ \\
Severe hypoglycemic event rate (events per 100 patient years) & 0.00 & 0.70 \\
Non-severe hypoglycemic event rate (events per 100 patient years) & 223.00 & $504.60^{\mathrm{a}}$
\end{tabular}

HbAlc glycated hemoglobin, $H D L$ high density lipoprotein, $L D L$ low density lipoprotein

a Statistically significant difference at $95 \%$ confidence level. It should be noted that HbAlc changes presented for each treatment arm by Lingvay et al. are not adjusted for differences between the IDegLira and insulin glargine arms at baseline, but the estimated treatment difference presented is adjusted for these differences [12]. The present analysis used the adjusted values for each treatment arm, reflecting the estimated treatment difference between the arms presented by Lingvay et al.

IDegLira and insulin glargine U100 used to calculate annual costs of treatment were taken from the DUAL V trial at 26 weeks based on wholesale acquisition costs (Table 4) [12, 18]. Costs of self-monitoring of blood glucose (SMBG) testing were based on an analysis of insurance claims in the USA [19]. Cost of diabetes-related complications were taken from US-specific sources and inflated to 2015 values if necessary using the consumer price index for health (Table 5) [19].

\section{Sensitivity Analyses}

A number of sensitivity analyses were conducted to identify key drivers of outcomes in the base case analysis and the robustness of this. The influence of time horizon on the model outcomes was assessed by running the analysis over 20 and 10 years. It should be noted that these analyses do not capture all late-stage, long-term outcomes, as some patients were still alive at the end of these simulations. The effect of discount rates on future costs and clinical outcomes were investigated through analyses in which they were set (symmetrically) to $0 \%$ and
$6 \%$ per annum. The key drivers of clinical outcomes were assessed by abolishing the differences in individual clinical parameters between the IDegLira arm and the insulin glargine U100 arm in turn. An additional analysis with only the statistically significant differences between IDegLira and insulin glargine U100 was conducted (Table 2).

Two alternative approaches to HbA1c progression were explored (see electronic supplementary material). In the first, no HbA1c changes were applied following the treatment effects applied in the first year of the analysis. This attempts to capture the legacy effect, where an early improvement in HbA1c has a benefit in the later years of life, even if the HbA1c difference no longer persists. In the second, the United Kingdom Prospective Diabetes Study (UKPDS) HbA1c progression equation was applied in both arms of the simulation. HbA1c increases over time in both arms of the analysis, with the HbA1c benefit in the IDegLira arm gradually reduced. Analyses were run with the upper and lower 95\% confidence interval of the HbA1c change seen in the IDegLira arm of DUAL $\mathrm{V}$ applied, with all other parameters in 
Table 3 Health state utilities used in the modeling analysis

\begin{tabular}{lrl}
\hline Complication & Utility & References \\
\hline Diabetes, no complications & 0.814 & {$[31]$} \\
Myocardial infarction, year of & -0.129 & {$[31]$} \\
$\quad$ event & & \\
Myocardial infarction, years 2+ & 0.736 & {$[31]$} \\
Angina & 0.682 & {$[31]$} \\
Congestive heart failure & 0.633 & {$[31]$} \\
Stroke, year of the event & -0.181 & {$[31]$} \\
Stroke, years 2+ & 0.545 & {$[31]$} \\
Peripheral vascular disease & 0.57 & {$[32]$} \\
Microalbuminuria & 0.814 & {$[31]$} \\
Gross proteinuria & 0.814 & {$[31]$} \\
Hemodialysis & 0.490 & {$[32]$} \\
Peritoneal dialysis & 0.560 & {$[32]$} \\
Renal transplant & 0.762 & {$[32]$} \\
Background diabetic retinopathy & 0.814 & {$[31]$} \\
Background diabetic retinopathy, & 0.814 & {$[31]$} \\
wrongly treated & & \\
Proliferative diabetic retinopathy & 0.794 & {$[26]$} \\
Proliferative diabetic retinopathy, & 0.794 & {$[26]$} \\
no laser & & \\
Macular edema & 0.794 & {$[26]$} \\
Severe vision loss & 0.734 & {$[31]$} \\
Cataract & 0.794 & {$[31]$} \\
Neuropathy & 0.624 & {$[26]$} \\
Healed ulcer & 0.814 & {$[31]$} \\
Active ulcer & 0.600 & {$[26]$} \\
Amputation, year of event & -0.109 & {$[31]$} \\
Nonputation, years 2+ hypoglycemia & 0.680 & {$[31]$} \\
\hline kach unit of body mass index over & -0.0061 & {$[34]$} \\
\hline & & \\
\hline
\end{tabular}

the IDegLira and insulin glargine U100 arms remaining unchanged. The base case analyses assumed that the BMI difference between the treatment arms was abolished on treatment switching, and an alternative to this was explored in a sensitivity analysis with the difference maintained for the duration of the analysis. The influence of treatment switching was assessed in analyses with treatment switching brought forward to 3 years in both arms, pushed back to 7 years in both arms, and no treatment switching.

The effect of over- or underestimating the direct cost of treating diabetes-related complications was investigated in two scenarios. In the first, the cost of treating complications was increased by $10 \%$, and in the second the cost was reduced by $10 \%$. The impact of applying alternative disutilities for severe and non-severe hypoglycemic events was assessed by using the values published by Currie et al. ( -0.0118 per severe hypoglycemic event and -0.0035 per non-severe hypoglycemic event) [20]. A scenario was investigated in which $28 \%$ of patients in the insulin glargine U100 arm were assumed to require twice-daily insulin, incurring the cost of a further needle for subcutaneous injection, based on a 5-year parallel group study of insulin glargine U100 versus neutral protamine Hagedorn (NPH) insulin [21]. To investigate the impact of consumables on cost-effectiveness outcomes, a scenario was evaluated with costs of needles and SMBG testing excluded. The effect of the cost of basal insulin was investigated in an analysis with the cost of insulin glargine U100 replaced with the cost of NPH insulin.

In February 2014, an update to the IMS CORE Diabetes Model incorporating data from the UKPDS 82 was released, and an analysis using this version of the model has been conducted. While a validation study of the revised model has been published, the model proprietors suggest that the update is used in a sensitivity analysis, with the previous version being used in the base case [22]. Similarly, version 9.0 of the IMS CORE Diabetes Model was released in summer 2015, and this was used in a sensitivity analysis. To date, no validation studies or user 
Table 4 Annual treatment costs

\begin{tabular}{lll}
\hline & $\begin{array}{l}\text { IDegLira } \\
(\mathbf{\$})\end{array}$ & $\begin{array}{l}\text { Insulin glargine } \\
(\mathbf{\$})\end{array}$ \\
\hline Daily IDegLira cost & 26.05 & - \\
Daily insulin glargine cost & - & 16.40 \\
Daily needle costs & 0.46 & 0.40 \\
Daily SMBG cost & 1.63 & 1.63 \\
Total daily cost & 28.15 & 18.44 \\
Total annual cost & $10,280.24$ & 6733.53 \\
\hline
\end{tabular}

$\$ 2015$ US dollars, $S M B G$ self-monitoring of blood glucose

guide for the updated version of the model have been released and therefore it was not considered appropriate to use version 9.0 of the model for the base case analysis.

Probabilistic sensitivity analysis (PSA) was performed using the predefined function in the IMS CORE Diabetes Model. Cohort characteristics, treatment effects, complication costs, and utilities were sampled from distributions and the simulation was run using a second-order Monte Carlo approach. Cohorts of 1000 patients were run through the model 1000 times for the PSA, as results were not subject to random statistical variation with these settings.

\section{Modeling Approach}

In line with good practice guidance for economic evaluation of T2DM interventions, outcomes were projected over patient lifetimes to capture all relevant long-term complications and associated costs, and assess their impact on life expectancy and quality-adjusted life expectancy [23]. Future clinical benefits and costs were discounted at 3\% annually, based on health economic guidance for the USA [24]. In the USA, cost-effectiveness thresholds have been defined by the Institute for Clinical and Economic Review, with incremental cost-effectiveness ratios (ICERs) under $\$ 100,000$ per QALY gained described as high care value, ICERs in the range $\$ 100,000-150,000$ per QALY gained described as intermediate care value, and ICERs over $\$ 150,000$ described as low care value. The Institute for Clinical and Economic Review is a non-profit organization that is becoming increasingly influential in healthcare decision-making in the USA [25].

\section{Model Description}

The base case analysis was performed using version $8.5+$ of the IMS CORE Diabetes Model (IMS Health, Basel, Switzerland), a validated, non-product-specific diabetes policy analysis tool (version 9.0 was used in a sensitivity analysis) [26]. The model is based on a series of interdependent submodels that simulate the complications of diabetes (angina, myocardial infarction, congestive heart failure, stroke, peripheral vascular disease, diabetic retinopathy, macular edema, cataract, hypoglycemia, ketoacidosis, lactic acidosis, nephropathy and end-stage renal disease, neuropathy, foot ulcer and amputation, and non-specific mortality). Each submodel has a semi-Markov structure and uses time, state, time-in-state, and diabetes type-dependent probabilities derived from published sources. Monte Carlo simulation using tracker variables overcomes the memory-less properties of the standard Markov model, and allows interconnectivity and interaction between individual complication submodels. Long-term outcomes projected by the model have been validated against real-life data in 2004 and more recently in 2014 [22, 27].

\section{Compliance with Ethics Guidelines}

This article does not contain any new studies with human or animal subjects performed by any of the authors.

\section{RESULTS}

\section{Base Case}

IDegLira was associated with improved discounted life expectancy (by 0.18 years) and quality-adjusted life expectancy (by 0.27 quality-adjusted life years [QALYs]) versus insulin glargine U100 in patients with T2DM failing to 
Table 5 Costs of diabetes-related complications

\begin{tabular}{|c|c|c|}
\hline Complication & $\begin{array}{l}\text { Cost } \\
(\$)\end{array}$ & References \\
\hline $\begin{array}{l}\text { Myocardial infarction, year of } \\
\text { event }\end{array}$ & 15,538 & {$[35]$} \\
\hline Myocardial infarction, years $2+$ & 1881 & {$[35]$} \\
\hline Angina, year of onset & 3402 & {$[35]$} \\
\hline Angina, years $2+$ & 562 & {$[35]$} \\
\hline $\begin{array}{l}\text { Congestive heart failure, year of } \\
\text { onset }\end{array}$ & 11,753 & {$[35]$} \\
\hline Congestive heart failure, years $2+$ & 6001 & {$[35]$} \\
\hline Stroke, year of event & 6779 & {$[35]$} \\
\hline Stroke, years $2+$ & 948 & {$[35]$} \\
\hline Stroke, death within 30 days & 5831 & {$[35]$} \\
\hline Peripheral vascular disease, onset & 5158 & {$[35]$} \\
\hline $\begin{array}{l}\text { Peripheral vascular disease, years } \\
2+\end{array}$ & 1998 & {$[35]$} \\
\hline Hemodialysis, onset & 18,962 & {$[35]$} \\
\hline Hemodialysis, years $2+$ & 14,361 & {$[35]$} \\
\hline Peritoneal dialysis, onset & 29,000 & {$[35]$} \\
\hline Peritoneal dialysis, years $2+$ & 20,873 & {$[35]$} \\
\hline Kidney transplant, first year & 9525 & {$[35]$} \\
\hline Kidney transplant, years $2+$ & 6726 & {$[35]$} \\
\hline Non-severe hypoglycemia & 12 & {$[36]$} \\
\hline Severe hypoglycemia & 209 & {$[36]$} \\
\hline Laser treatment & 673 & {$[37]$} \\
\hline Cataract operation & 796 & {$[37]$} \\
\hline Cataract operation, years $2+$ & 145 & {$[35]$} \\
\hline Blindness, first year & 1165 & {$[35]$} \\
\hline Blindness, years 2+ & 284 & {$[35]$} \\
\hline Neuropathy, year of onset & 1972 & {$[35]$} \\
\hline Neuropathy, years $2+$ & 666 & {$[35]$} \\
\hline Amputation, procedure & 6855 & {$[35]$} \\
\hline Amputation, prosthesis & 2544 & {$[38,39]$} \\
\hline Gangrene treatment & 11,786 & [35] \\
\hline
\end{tabular}

Table 5 continued

\begin{tabular}{lcl}
\hline Complication & $\begin{array}{l}\text { Cost } \\
(\$)\end{array}$ & References \\
\hline Infected foot ulcer & 5936 & {$[35]$} \\
Uninfected foot ulcer & 5936 & {$[35]$} \\
Cost after healed ulcer & 2954 & {$[35]$} \\
\hline
\end{tabular}

$\$ 2015$ US dollars

achieve glycemic targets on basal insulin (Table 6). Clinical benefits resulted from a reduced incidence of diabetes-related complications in the IDegLira arm over the 50-year time horizon of the model. In addition to reducing the projected cumulative incidence of complications, IDegLira was associated with a delayed mean time to onset of diabetes-related complications. Mean time to onset of any diabetes-related complication in the modeling analysis was approximately 0.6 years longer with IDegLira than with insulin glargine U100, and benefits were observed across all micro- and macrovascular complications included in the analysis (Fig. 1).

Evaluation of direct costs suggested that the mean cost per patient in the IDegLira arm was $\$ 16,970$ higher than in the insulin glargine U100 arm over patient lifetimes (Fig. 2). The increased cost was driven by the increased acquisition cost of IDegLira compared with insulin glargine U100 over the first 5 years of the analysis. However, this increased cost was partially offset as a result of avoided diabetes-related complications, particularly cardiovascular complications (mean cost saving of \$527 per patient) and ulcer/amputation/neuropathy complications (mean cost saving of \$369 per patient).

Estimation of long-term cost-effectiveness outcomes indicated that both life expectancy and quality-adjusted life expectancy were improved with IDegLira treatment compared with insulin glargine U100, at an increased cost from a healthcare payer perspective. IDegLira was associated with an ICERe of $\$ 63,678$ per QALY gained versus insulin glargine U100 in patients failing to achieve glycemic control on basal insulin (Table 6). 
Table 6 Long-term cost-effectiveness outcomes

\begin{tabular}{llll}
\hline & $\begin{array}{l}\text { IDegLira } \\
{[\text { Mean }(\text { SD })]}\end{array}$ & $\begin{array}{l}\text { Insulin glargine U100 } \\
{[\text { mean }(\text { SD) }}\end{array}$ & Difference \\
\hline Discounted life expectancy (years) & $13.99(0.19)$ & $13.82(0.20)$ & +0.18 \\
Discounted quality-adjusted life expectancy (QALYs) & $9.14(0.12)$ & $8.87(0.13)$ & +0.27 \\
Discounted direct costs (\$) & $205,083(2757)$ & $188,113(2856)$ & $+16,970$ \\
ICER (life expectancy) & $\$ 96,039$ per life year gained & \\
ICER (quality-adjusted life expectancy) & $\$ 63,678$ per QALY gained & \\
\hline
\end{tabular}

Rows may not sum as a result of rounding

$\$ 2015$ US dollars, ICER incremental cost-effectiveness ratio, $Q A L Y s$ quality-adjusted life years, $S D$ standard deviation

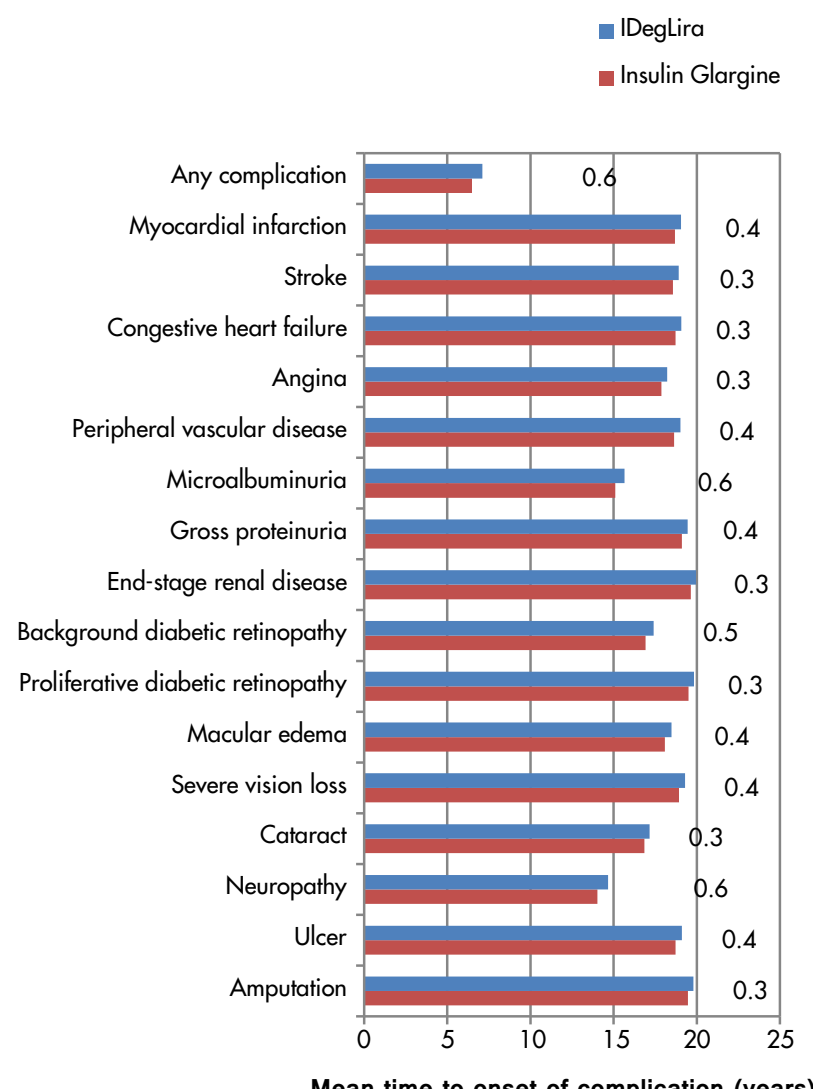

Fig. 1 Mean time to onset of complications. Data labels show the difference between the treatment arms

\section{Sensitivity Analyses}

Sensitivity analyses identified that changing the time horizon of the analysis had the most notable impact on the projected outcomes
(Table 7), with the clinical benefit reduced and a smaller increase in costs at shorter time horizons. This was primarily because improvements in physiological parameters associated with IDegLira reduced the risk of long-term 


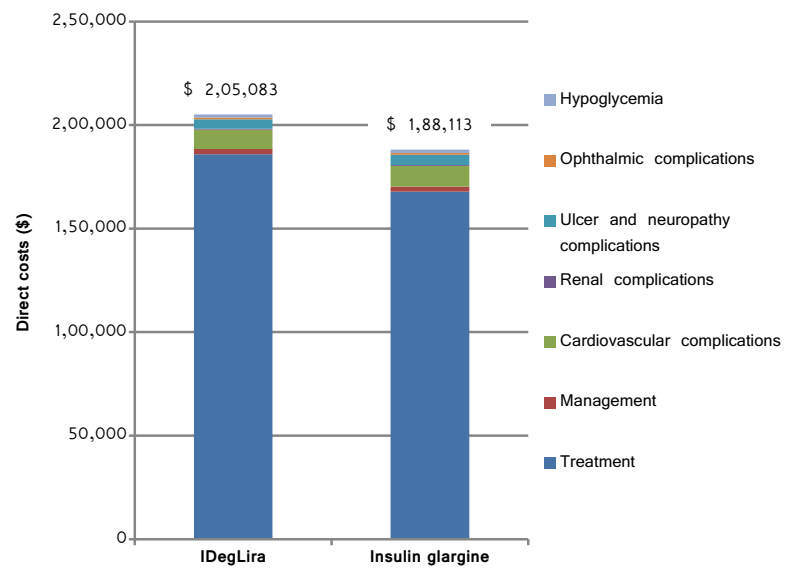

Fig. 2 Mean direct costs over patient lifetimes. \$ 2015 US dollars

complications. Altering the discount rates also reflected the long-term benefits associated with IDegLira, with clinical benefits increased and the ICER reduced when a discount rate of $0 \%$ was applied.

Also of note was the analysis in which only the statistically significant differences between the treatment arms were applied. This resulted in a small increase in the ICER, to $\$ 66,088$ per QALY gained. Abolishing each of the changes in physiological parameters associated with IDegLira identified that the key driver of improved clinical outcomes was a greater reduction in HbA1c. Abolishing this difference between the treatment arms resulted in quality-adjusted life expectancy benefit with IDegLira of 0.15 QALYs. However, improvements in other physiological parameters were also important in driving long-term benefits.

Applying an alternative $\mathrm{HbA} 1 \mathrm{c}$ progression with no increases applied at any stage of the analysis (attempting to replicate the legacy effect) resulted in an increased clinical benefit in the IDegLira arm, with the ICER falling to $\$ 44,558$ per QALY gained. Application of the UKPDS HbA1c progression equation resulted in a slightly smaller clinical benefit with IDegLira over insulin glargine U100, with a small increase in the ICER to $\$ 74,968$ per QALY gained. Using the upper of lower 95\% confidence limits of the HbA1c change in the IDegLira arm resulted in only small changes in the cost and clinical outcomes calculated.
Maintaining the body mass index difference between the arms for the duration of the analysis resulted in a reduced ICER owing to a greater clinical benefit with IDegLira over insulin glargine U100.

Changing the assumptions around treatment switching had a notable impact on the calculated health economic outcomes. Maintaining patients on IDegLira for longer increased the incremental clinical benefit, but also increased the incremental cost. Assuming that patients remained on IDegLira or insulin glargine U100 for the duration of their lifetime led to a quality-adjusted life expectancy benefit of 0.58 QALYs at an increased cost of $\$ 50,776$. This resulted in an ICER of $\$ 87,334$ per QALY gained.

Increasing the cost of complications resulted in the ICER falling, while reducing the cost of complications had the converse effect. Assuming that $28 \%$ of patients in the insulin glargine U100 arm required twice-daily insulin injections resulted in a reduced ICER of $\$ 63,023$ per QALY gained. Applying the cost of NPH insulin in the insulin glargine U100 arm resulted in an increased ICER of $\$ 106,423$ per QALY gained. However, use of NPH is very low in the USA, making this scenario unlikely in most populations. Removing the cost of SMBG tests and needles, and application of alternative hypoglycemia disutilities resulted in only small changes in the calculated outcomes. Using the UKPDS 82 risk equations and version 9.0 of the IMS CORE Diabetes Model to project outcomes resulted in small reductions in the clinical benefit associated with IDegLira and small increases in the ICER.

PSA suggested that at a willingness to pay threshold of $\$ 100,000$ per QALY gained, there was a $69.6 \%$ probability that IDegLira would be considered cost-effective compared with insulin glargine U100.

\section{DISCUSSION}

Based on data from the DUAL V trial, the present modeling study found that IDegLira was associated with improved long-term clinical outcomes versus insulin glargine U100 in 
Table 7 Sensitivity analyses

\begin{tabular}{|c|c|c|c|c|c|c|c|}
\hline & \multicolumn{3}{|c|}{$\begin{array}{l}\text { Discounted quality-adjusted } \\
\text { life expectancy (QALYs) }\end{array}$} & \multicolumn{3}{|c|}{ Discounted costs $(\$)$} & \multirow{2}{*}{$\begin{array}{l}\text { ICER } \\
\text { (\$ per QALY } \\
\text { gained) }\end{array}$} \\
\hline & IDegLira & $\begin{array}{l}\text { Insulin } \\
\text { glargine } \\
\text { U100 }\end{array}$ & $\overline{\text { Difference }}$ & IDegLira & $\begin{array}{l}\text { Insulin } \\
\text { glargine } \\
\text { U100 }\end{array}$ & $\overline{\text { Difference }}$ & \\
\hline Base case & 9.14 & 8.87 & +0.27 & 205,083 & 188,113 & $+16,970$ & 63,678 \\
\hline 20-year time horizon & 7.99 & 7.78 & +0.20 & 169,494 & 153,744 & $+15,750$ & 77,095 \\
\hline 10-year time horizon & 5.37 & 5.23 & +0.14 & 101,310 & 85,986 & $+15,325$ & 107,090 \\
\hline $0 \%$ discount rates & 12.78 & 12.40 & +0.39 & 303,710 & 283,663 & $+20,047$ & 51,841 \\
\hline $6 \%$ discount rates & 6.94 & 6.74 & +0.20 & 148,343 & 133,371 & $+14,972$ & 75,389 \\
\hline HbAlc difference abolished & 9.03 & 8.87 & +0.15 & 204,313 & 188,113 & $+16,201$ & 104,926 \\
\hline $\begin{array}{l}\text { Blood pressure difference } \\
\text { abolished }\end{array}$ & 9.11 & 8.87 & +0.23 & 204,663 & 188,113 & $+16,550$ & 70,668 \\
\hline Lipid difference abolished & 9.11 & 8.87 & +0.23 & 204,562 & 188,113 & $+16,450$ & 70,148 \\
\hline BMI difference abolished & 9.09 & 8.87 & +0.22 & 204,951 & 188,113 & $+16,839$ & 77,456 \\
\hline $\begin{array}{l}\text { Hypoglycemia difference } \\
\text { abolished }\end{array}$ & 9.08 & 8.87 & +0.21 & 205,138 & 188,113 & $+17,026$ & 82,409 \\
\hline $\begin{array}{l}\text { Statistically significant differences } \\
\text { only }\end{array}$ & 9.13 & 8.87 & +0.26 & 204,939 & 188,113 & $+16,826$ & 66,088 \\
\hline HbAlc benefit maintained & 9.24 & 8.87 & +0.37 & 204,577 & 188,113 & $+16,464$ & 44,558 \\
\hline UKPDS HbAlc creep & 8.53 & 8.31 & +0.22 & 203,443 & 187,309 & $+16,133$ & 74,968 \\
\hline $\begin{array}{l}\text { Upper } 95 \% \mathrm{CI} \text { of } \mathrm{HbAlc} \text { change } \\
\text { in IDegLira arm }\end{array}$ & 9.14 & 8.87 & +0.27 & 204,885 & 188,113 & $+16,772$ & 61,889 \\
\hline $\begin{array}{l}\text { Lower } 95 \% \text { CI of HbAlc change } \\
\text { in IDegLira arm }\end{array}$ & 9.11 & 8.87 & +0.24 & 204,685 & 188,113 & $+16,573$ & 69,957 \\
\hline $\begin{array}{l}\text { BMI benefit maintained after } \\
\text { treatment switch }\end{array}$ & 9.21 & 8.87 & +0.34 & 205,012 & 188,113 & $+16,900$ & 50,342 \\
\hline $\begin{array}{l}\text { Treatment switching at } 3 \text { years in } \\
\text { both arms }\end{array}$ & 9.00 & 8.83 & +0.18 & 210,811 & 200,240 & $+10,571$ & 60,267 \\
\hline $\begin{array}{l}\text { Treatment switching at } 7 \text { years in } \\
\text { both arms }\end{array}$ & 9.23 & 8.93 & +0.30 & 199,189 & 177,525 & $+21,664$ & 72,844 \\
\hline No switching & 9.79 & 9.20 & +0.58 & 167,155 & 116,380 & $+50,776$ & 87,334 \\
\hline Costs of complications $+10 \%$ & 9.14 & 8.87 & +0.27 & 206,758 & 189,901 & $+16,857$ & 63,255 \\
\hline Costs of complications $-10 \%$ & 9.14 & 8.87 & +0.27 & 203,460 & 186,382 & $+17,078$ & 64,082 \\
\hline Currie et al. hypo utilities applied & 9.24 & 8.98 & +0.26 & 205,083 & 188,113 & $+16,970$ & 66,186 \\
\hline $\begin{array}{l}28 \% \text { of basal insulin patients } \\
\text { twice daily }\end{array}$ & 9.14 & 8.87 & +0.27 & 205,497 & 188,702 & $+16,796$ & 63,023 \\
\hline
\end{tabular}


Table 7 continued

\begin{tabular}{|c|c|c|c|c|c|c|c|}
\hline & \multicolumn{3}{|c|}{$\begin{array}{l}\text { Discounted quality-adjusted } \\
\text { life expectancy (QALYs) }\end{array}$} & \multicolumn{3}{|c|}{ Discounted costs $(\$)$} & \multirow{2}{*}{$\begin{array}{l}\text { ICER } \\
\text { (\$ per QALY } \\
\text { gained) }\end{array}$} \\
\hline & IDegLira & $\begin{array}{l}\text { Insulin } \\
\text { glargine } \\
\text { U100 }\end{array}$ & Difference & IDegLira & $\begin{array}{l}\text { Insulin } \\
\text { glargine } \\
\text { U100 }\end{array}$ & Difference & \\
\hline $\begin{array}{l}\text { Needle and SMBG costs not } \\
\text { included }\end{array}$ & 9.14 & 8.87 & +0.27 & 183,893 & 167,312 & $+16,581$ & 62,216 \\
\hline $\begin{array}{l}\text { NPH cost applied in insulin } \\
\text { glargine U100 arm }\end{array}$ & 9.14 & 8.87 & +0.27 & 179,553 & 151,191 & $+28,362$ & 106,423 \\
\hline UKPDS 82 equations applied & 9.36 & 9.14 & +0.22 & 212,124 & 195,552 & $+16,572$ & 74,279 \\
\hline $\begin{array}{l}\text { Version } 9.0 \text { of the IMS CORE } \\
\text { Diabetes Model }\end{array}$ & 9.05 & 8.80 & +0.25 & 207,629 & 191,407 & $+16,222$ & 65,413 \\
\hline PSA & 8.73 & 8.50 & +0.23 & 198,024 & 181,882 & $+16,142$ & 70,182 \\
\hline
\end{tabular}

Rows may not sum as a result of rounding

$\$ 2015$ US dollars, BMI body mass index, $C I$ confidence interval, HbAlc glycated hemoglobin, NPH neutral protamine Hagedorn, PSA probabilistic sensitivity analysis, $Q A L Y$ quality-adjusted life year, $S M B G$ self-monitoring of blood glucose, UKPDS United Kingdom Prospective Diabetes Study

patients with T2DM failing to achieve glycemic control on basal insulin. Improved life expectancy and quality-adjusted life expectancy resulted from reduced incidence and increased time to onset of complications owing to improvements in risk factors, including HbA1c, blood pressure, serum lipid levels, BMI, and hypoglycemic event rates. The favorable changes across these parameters reflect the multifactorial benefits of treatment with IDegLira. IDegLira was associated with increased costs, driven by the higher acquisition cost versus insulin glargine U100 over the first 5 years of the analysis. However, this was partially offset by avoided costs of treating diabetes-related complications. IDegLira was associated with an ICER of $\$ 63,678$ per QALY gained versus insulin glargine U100 in patients with T2DM in the USA failing to achieve glycemic control on basal insulin. This ICER is within the range described as high care value by the Institute for Clinical and Economic Review in the USA (high care value $<\$ 100,000$ per QALY gained), and therefore IDegLira is likely to be considered cost-effective.
IDegLira represents an alternative treatment strategy for patients with T2DM not achieving glycemic control on basal insulin. IDegLira is combined in a fixed ratio in a single-injection device, representing a simple treatment option for patients without the need for addition of multiple daily injections, which is likely to be attractive to both patients and payers [28]. As well as allowing patients to receive appropriate doses to improve glycemic control, slower titration of GLP-1 receptor agonists has been shown to reduce the frequency of adverse events, such as nausea, and this may represent an additional benefit of IDegLira [29]. The complementary mechanisms of action of a basal insulin and a GLP-1 receptor agonist within IDegLira result in the ability to achieve glycemic control while mitigating the risk of hypoglycemia and weight gain compared to other therapy options, such as increasing doses of basal insulin.

In the DUAL $\mathrm{V}$ study, IDegLira was also associated with improved patient-reported outcomes compared to insulin glargine U100 [12]. The Short Form 36 (SF-36) health survey 
identified an improvement in the physical component over the duration of the trial in the IDegLira arm, but a reduction in the insulin glargine U100 arm (estimated treatment difference $1.9,95 \%$ confidence interval 0.8-3.1). This was predominantly driven by differences in the physical functioning and pain subdomains. No differences between the treatments were observed in the mental health component or any of its subdomains. Diabetes-specific patient-reported outcomes, as measured by the Treatment Related Impact Measures-Diabetes (TRIM-D) showed improvements in both treatment arms, but these were greater in the IDegLira arm. This was largely driven by higher scores in the treatment burden and diabetes management, subdomains, indicating higher treatment satisfaction with IDegLira (overall estimated treatment difference $2.8,95 \%$ confidence interval 0.9-4.7).

A potential limitation of the analysis may be the open-label nature of the DUAL V trial [12]. As a result of the IDegLira dose cap (50 dose steps), achieving a double-blinded study would have required a dummy-dummy design, with patients administering two injections per day from unlabeled syringes. The open-label design may have led to different expectations of the study medications, which in turn may have affected adverse event reporting and/or adherence to lifestyle recommendations. It is difficult to quantify the impact the open-label design may have had on the DUAL $\mathrm{V}$ study and therefore the present analysis. However, changes in HbA1c, body weight, and hypoglycemic event rates were similar to the double-blinded DUAL II trial, which was also conducted in patients failing to achieve glycemic control on basal insulin [12, 30].

As with many health economic evaluations, particularly those of interventions for T2DM, a limitation of the present analysis may be using short-term clinical trial data to make long-term projections of clinical and cost outcomes. To minimize the impact of this, a widely published model of diabetes with extensive validation against real-life data was used [22, 27]. The analysis was also conducted in line with guidelines for economic evaluation of interventions for patients with T2DM, which recommends projecting outcomes over patient lifetimes [23].

\section{CONCLUSION}

Based on head-to-head clinical trial data, the present analysis suggests that IDegLira is likely to improve long-term clinical outcomes for patients with T2DM not achieving glycemic control on basal insulin compared to re-education and up-titration of the dose of insulin glargine U100. The improvements came at an increased cost from a healthcare payer perspective, although cost savings as a result of avoided diabetes-related complications were identified. IDegLira was associated with an ICER of $\$ 63,678$ per quality-adjusted life year QALY gained. This ICER is within the range described as high care value by the Institute for Clinical and Economic Review in the USA (high care value $<\$ 100,000$ per QALY gained), and therefore IDegLira is likely to be considered cost-effective.

\section{ACKNOWLEDGEMENTS}

Sponsorship and article processing charges for this study were funded by Novo Nordisk A/S and Novo Nordisk Inc.

All named authors meet the International Committee of Medical Journal Editors (ICMJE) criteria for authorship for this manuscript and take responsibility for the integrity of the work as a whole, and have given final approval to the version to be published.

All authors had full access to all of the data in this study and take complete responsibility for the integrity of the data and accuracy of the data analysis.

Disclosures. Barnaby Hunt is an employee of Ossian Health Economics and Communications, which received consulting fees from Novo Nordisk A/S and Novo Nordisk Inc. to support preparation of the analysis. William Valentine is an employee of Ossian Health Economics and Communications, which received consulting fees from Novo Nordisk A/S 
and Novo Nordisk Inc. to support preparation of the analysis. Michelle Mocarski is an employee of Novo Nordisk Inc. Jakob Langer is an employee and shareholder of Novo Nordisk $\mathrm{A} / \mathrm{S}$.

Compliance with Ethics Guidelines. This article does not contain any new studies with human or animal subjects performed by any of the authors.

Data Availability. The datasets during and/ or analyzed during the current study are available from the corresponding author on reasonable request.

Open Access. This article is distributed under the terms of the Creative Commons Attribution-NonCommercial 4.0 International License (http://creativecommons.org/licenses/ by-nc/4.0/), which permits any noncommercial use, distribution, and reproduction in any medium, provided you give appropriate credit to the original author(s) and the source, provide a link to the Creative Commons license, and indicate if changes were made.

\section{REFERENCES}

1. Zhang P, Zhang X, Brown J, et al. Global healthcare expenditure on diabetes for 2010 and 2030. Diabetes Res Clin Pract. 2010;87(3):293-301.

2. American Diabetes Association. Economic costs of diabetes in the US in 2012. Diabetes Care. 2013;36:1033-46.

3. UK Prospective Diabetes Study Group. UK prospective diabetes study 16: overview of 6 years' therapy of type II diabetes: a progressive disease. Diabetes. 1995;44(11):1249-58.

4. Nathan DM. Clinical practice. Initial management of glycemia in type 2 diabetes mellitus. N Engl J Med. 2002;347(17):1342-9.

5. Russell-Jones D, Khan R. Insulin-associated weight gain in diabetes-causes, effects and coping strategies. Diabetes Obes Metab. 2007;9(6):799-812.

6. Eng C, Kramer CK, Zinman B, Retnakaran R. Glucagon-like peptide-1 receptor agonist and basal insulin combination treatment for the management of type 2 diabetes: a systematic review and meta-analysis. Lancet. 2014;384(9961):2228-34.

7. American Diabetes Association. 7. Approaches to glycemic treatment. Diabetes Care. 2016;39:S52-9.

8. Davies MJ, Glah D, Chubb B, Konidaris G, McEwan P. Cost effectiveness of IDegLira vs. alternative basal insulin intensification therapies in patients with type 2 diabetes mellitus uncontrolled on basal insulin in a UK setting. Pharmacoeconomics. 2016;34(9):953-66.

9. Ericsson $\AA$, Lundqvist A. Cost effectiveness of insulin degludec plus liraglutide (IDegLira) in a fixed combination for uncontrolled type 2 diabetes mellitus in Sweden. Appl Health Econ Health Policy. 2017;15(2):237-48.

10. Prades M, Lizan L, Hunt B, Ramirez de Arellano A. Long-term cost utility analysis of IDegLira versus basal-bolus insulin intensification therapies in patients with type 2 diabetes inadequately controlled on basal insulin in Spain. Val Health. 2016;19(3):A99.

11. Hunt B, Mocarski M, Valentine WJ, Langer J. Evaluation of the long-term cost-effectiveness of ideglira versus liraglutide added to basal insulin for patients with type 2 diabetes failing to achieve glycemic control on basal insulin in the USA. 2017. doi:10.1080/13696998.2017.1301943.

12. Lingvay I, Manghi FP, García-Hernández P, et al. Effect of insulin glargine up-titration vs insulin degludec/liraglutide on glycated hemoglobin levels in patients with uncontrolled type 2 diabetes: the DUAL V randomized clinical trial. JAMA. 2016;315(9):898-907.

13. Wright A, Burden AC, Paisey RB, Cull CA, Holman RR. Sulfonylurea inadequacy: efficacy of addition of insulin over 6 years in patients with type 2 diabetes in the UK Prospective Diabetes Study (UKPDS 57). Diabetes Care. 2002;25(2):330-6.

14. Holman RR, Farmer AJ, Davies MJ, et al. Three-year efficacy of complex insulin regimens in type 2 diabetes. N Engl J Med. 2009;361(18):1736-47.

15. Duckworth W, Abraira C, Moritz T, et al. Glucose control and vascular complications in veterans with type 2 diabetes. N Engl J Med. 2009;360(2):129-39.

16. Gerstein HC, Miller ME, Byington RP, et al. Effects of intensive glucose lowering in type 2 diabetes. N Engl J Med. 2008;358(24):2545-59.

17. Patel A, MacMahon S, Chalmers J, et al. Intensive blood glucose control and vascular outcomes in patients with type 2 diabetes. $\mathrm{N}$ Engl J Med. 2008;358(24):2560-72. 
18. Medi-Span Price Rx. http://www.wolterskluwercdi. com/price-rx/. Accessed 16 Oct 2017.

19. Yeaw J, Lee WC, Aagren M, Christensen T. Cost of self-monitoring of blood glucose in the United States among patients on an insulin regimen for diabetes. J Manag Care Pharm. 2012;18(1):21-32.

20. Currie CJ, Morgan CL, Poole CD, Sharplin P, Lammert M, McEwan P. Multivariate models of health-related utility and the fear of hypoglycaemia in people with diabetes. Curr Med Res Opin. 2006;22(8):1523-34.

21. Rosenstock J, Fonseca V, McGill JB, et al. Similar progression of diabetic retinopathy with insulin glargine and neutral protamine Hagedorn (NPH) insulin in patients with type 2 diabetes: a long-term, randomised, open-label study. Diabetologia. 2009;52(9):1778-88.

22. McEwan P, Foos V, Palmer JL, Lamotte M, Lloyd A, Grant D. Validation of the IMS CORE diabetes model. Value Health. 2014;17(6):714-24.

23. American Diabetes Association Consensus Panel. Guidelines for computer modeling of diabetes and its complications. Diabetes Care. 2004;27(9):2262-5.

24. Gold MR, Siegel JE, Russell LB, Weinstein MC. Cost-effectiveness in health and medicine. New York: Oxford University Press; 1996.

25. Pizzi LT. The Institute for Clinical and Economic Review and its growing influence on the US healthcare. Am Health Drug Benefits. 2016;9(1):9-10.

26. Palmer AJ, Roze S, Valentine WJ, et al. The CORE Diabetes Model: projecting long-term clinical outcomes, costs and cost-effectiveness of interventions in diabetes mellitus (types 1 and 2) to support clinical and reimbursement decision-making. Curr Med Res Opin. 2004;20(Suppl 1):5-26.

27. Palmer AJ, Roze S, Valentine W, et al. Validation of the CORE Diabetes Model against epidemiological and clinical studies. Curr Med Res Opin. 2004;20(Suppl 1):27-40.

28. Boye KS, Matza LS, Walter KN, Van Brunt K, Palsgrove AC, Tynan A. Utilities and disutilities for attributes of injectable treatments for type 2 diabetes. Eur J Health Econ. 2011;12(3):219-30.

29. Cefalu WT, Buse JB, Del Prato S, et al. Beyond metformin: safety considerations in the decision-making process for selecting a second medication for type 2 diabetes management: reflections from a diabetes care editors' expert forum. Diabetes Care. 2014;37(9):2647-59.

30. Buse JB, Vilsbøll T, Thurman J, et al. NN9068-3912 (DUAL-II) Trial Investigators. Contribution of liraglutide in the fixed-ratio combination of insulin degludec and liraglutide (IDegLira). Diabetes Care. 2014;37(11):2926-33.

31. Clarke P, Gray A, Holman R. Estimating utility values for health states of type 2 diabetic patients using the EQ-5D (UKPDS 62). Med Decis Making. 2002;22(4):340-9.

32. Tengs TO, Wallace A. One thousand health-related quality-of-life estimates. Med Care. 2000;38(6): 583-637.

33. Evans M, Khunti K, Mamdani M, et al. Health-related quality of life associated with daytime and nocturnal hypoglycaemic events: a time trade-off survey in five countries. Health Qual Life Outcomes. 2013;11(1):90.

34. Bagust A, Beale S. Modelling EuroQol health-related utility values for diabetic complications from CODE-2 data. Health Econ. 2005;14(3):217-30.

35. Yeaw J, Halinan S, Hines D, et al. Direct medical costs for complications among children and adults with diabetes in the US commercial payer setting. Appl Health Econ Health Policy. 2014;12(2): 219-30.

36. Foos V, Varol N, Curtis BH, et al. Economic impact of severe and non-severe hypoglycemia in patients with type 1 and type 2 diabetes in the United States. J Med Econ. 2015;18(6):420-32.

37. Ramulu PY, Do DV, Corcoran KJ, Robin AL. Use of retinal procedures in medicare beneficiaries from 1997 to 2007. Arch Ophthalmol. 2010;128(10): 1335-40.

38. Department of Health and Human Services. Questionable billing by suppliers of lower limb prostheses. https://oig.hhs.gov/oei/reports/oei-02-1000170.pdf. Accessed 16 Oct 2017.

39. Carroll K. Older adults can thrive as prosthesis users. Senior Step. http://www.amputee-coalition.org/ senior_step/older_prosthesis_users.html. Accessed 16 Oct 2017. 